\title{
The right resources to support LIS research: findings from the RiLIES2 project poll
}

\author{
Peter Cruickshank, Hazel Hall, Christine Irving
}

\begin{abstract}
In 2011 and 2012 the Library and Information Science Research Coalition supported two projects entitled Research in Librarianship Impact Evaluation Study (RiLIES1 and RiLIES2). This paper discusses the results of a survey completed in spring 2012 as part of RiLIES2. RiLIES2 was concerned with the production of a series of outputs such as training, good practice and community support materials, to support the identification, use and execution of research by librarians and information scientists. The purpose of the survey was to determine which of the existing resources which purported to support librarians and information scientists in using or conducting research were (a) well used; (b) respected. The survey's main findings revealed a low level of awareness of the full range of existing resources to support LIS research and highlighted the pressing need for a centrally-funded community-maintained directory of LIS research resources, held in a known location, with (crucially) a long-term commitment to maintenance.
\end{abstract}

\section{Authors}

Peter Cruickshank is a Research Fellow at the Centre for Social Informatics within the Institute for Informatics and Digital Innovation at Edinburgh Napier University. His research interests include project evaluation, knowledge planning, e-participation, and the uptake of information systems.

Professor Hazel Hall is Director of the Centre for Social Informatics within the Institute for Informatics and Digital Innovation at Edinburgh Napier University. Between 2009 and 2012 she led the implementation of the UK Library and Information Science Research Coalition.

Christine Irving is a freelance information professional. She joined the Centre for Social Informatics within the Institute for Informatics and Digital Innovation at Edinburgh Napier University in 2012 to work part-time with the RiLIES project team. A chartered library and information professional, Christine is also Secretary of the Library and Information Research Group (LIRG).

Email: p.cruickshank@napier.ac.uk 


\section{Introduction}

In 2011 the UK Library and Information Science Research Coalition supported a six-month research project which investigated the extent to which funded research projects in the domain of library and information science (LIS) influence practice. The Research in Librarianship Impact Evaluation Study (RiLIES) focused on the identification of factors that increase or hinder the impact of research findings on those who deliver library and information services. The project's findings largely confirmed that there is a disconnect between LIS research and practitioner communities. They also revealed that the level of impact that research projects enjoy depends on a number of factors, most importantly:

1. How a project is planned and conceived;

2. The extent to which practitioners are involved in the execution of a project;

3. How project findings are reported.

Organisational factors that support a receptive target audience for research output are also of significance to the question of research impact in practice. The full project report Enhancing the impact of LIS research projects was published by the Research Information Network in February 2012 and is freely available to download (Cruickshank, Hall and Taylor-Smith, 2011).

In response to the findings of the RiLIES work, a successor project was established. RiLIES2 was concerned with the production of a series of outputs such as training, good practice and community support materials, to support the identification, use and execution of research by librarians and information scientists.

The RiLIES2 project team was keen to ensure that this follow-on work would not replicate existing resources. Related to this, it was important to identify the best format and "home" for any new resources created as part of the project. Therefore in April 2012 UK-based LIS professionals were invited to take part in a short poll. The poll's findings were used to determine which of the existing resources which purport to support librarians and information scientists in using / conducting research are:

a. Well used;

b. Respected.

This article summarises the findings of the poll.

\section{Methodology}

An online survey was created using the same tool (SurveyGizmo) which had been successfully used in earlier phases of the RiLIES project. One advantage of this approach was that it was easy to collect comparable demographic information.

The survey was aimed at LIS professionals based in the UK. LIS professionals from other countries were also welcome to respond.

JISC mailing lists, supplemented by active tweeting from the LIS Research Coalition accounts (@LISResearch and @LIS_RiLIES in particular),were the 
main routes to target invitations for participation at LIS professionals. We would also like to acknowledge the support of Information Today Europe (http://www.infotodayeurope.com/) in publicising the survey.

87 responses were received, 78 (90\%) of which derived from the UK. The majority of respondents (54, i.e. 62\%) were academic librarians (Figure 1). Just 4 responses were received from public librarians. The low response rate from this sector was an issue also encountered in the RiLIES1 project. Indeed, this problem has also been encountered by others when completing LIS research projects.

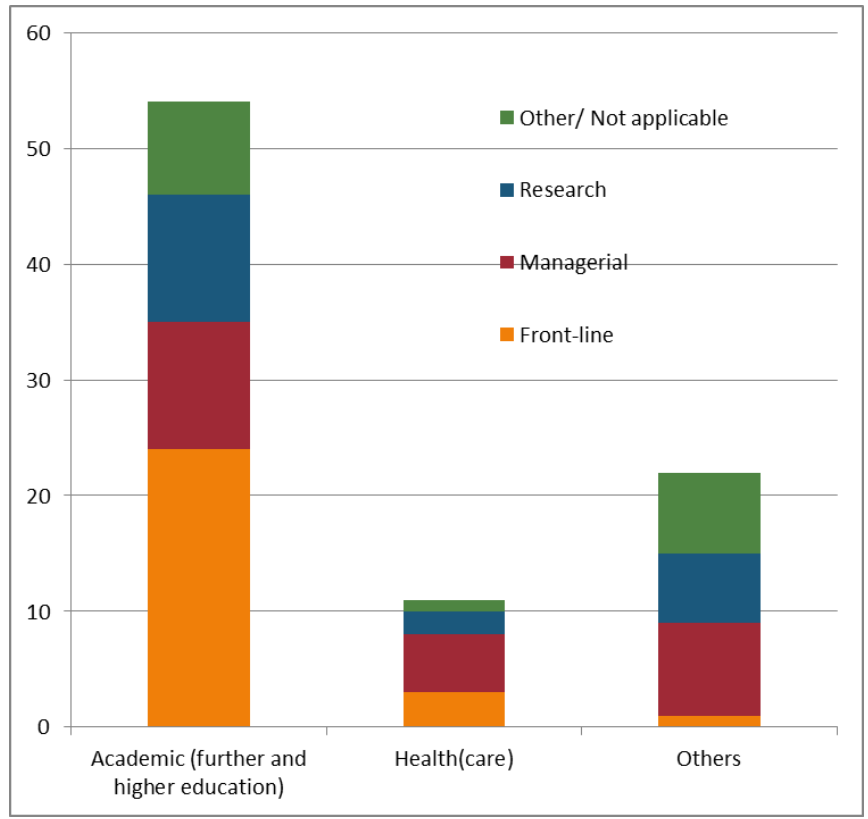

Figure 1: Summary of responses

The relatively low response rate to the survey as a whole constrains the level of analysis that is possible, particularly in extrapolating our findings beyond the academic librarian community. However, the data could be treated qualitatively as a useful source of new ideas to be evaluated and used in the middle of the study to adjust the project plans.

The main findings from the survey are discussed in the next section.

\section{Survey results}

\subsection{Research results: Sources of information}

The first question asked about respondents' knowledge and experience of a list of 19 electronic resources. These had previously been identified from the RiLIES1 study, and through desk research in the early stages of RiLIES2. The results in Figure 1 are sorted so that the resources found to be most useful are at the top. The data shows that six resources have evidence of being appreciated by most respondents:

1. JISC mailing lists;

2. Library and Information Research (journal); 
3. CILIP's Library and Information Research Group (LIRG);

4. Evidence Based Library and Information Practice (EBLIP) (journal);

5. Blogs;

6. Twitter feeds.

The resources generated by the RiLIES sister project Developing Research Excellence and Methods (DREaM) was an honourable runner up.

Respondents' comments supported previous findings that mailing lists (particularly operated by JISC (https://www.jiscmail.ac.uk/ )) continue to be the main source of information for many who are interested in research. A possibly related observation is that a number of resources (circled in Figure 2) have still to get their audience to move from "heard of it" to "have tried it": particular examples are the DREaM resources, the EBLIP journal and LIRG.

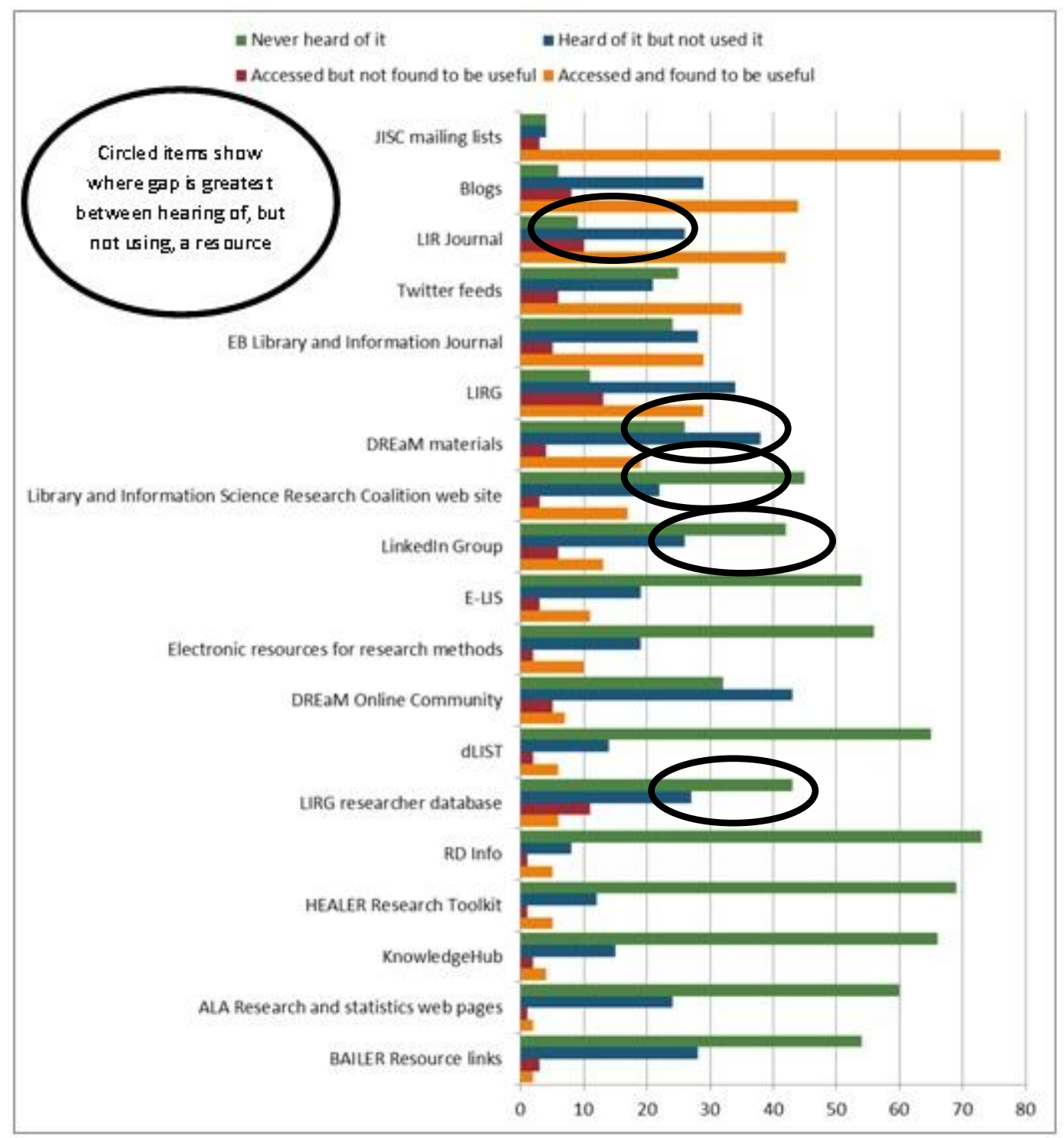

Figure 2: Awareness and use of resources 
Another issue is that some of the resources identified have been found to be wanting. A large proportion of respondents reported that they had accessed particular resources, but not found them useful. This applied to two sets of resources which rely on volunteer effort for their maintenance:

1. web pages of the Library and Information Research Group (LIRG);

2. BAILER resource links.

Long-term commitment to resource curation is a key issue here.

Many respondents had simply not heard of a number of the resources listed in the survey. This was even the case for academic LIS practitioners. Amongst the less "visible" resources were some based in the US, such as dLIST, RD Info and ALA. In addition, Knowledge Hub (http://knowledgehub.local.gov.uk/), which is potentially a key UK community-site for public sector workers, was little known. Knowledge Hub is hosted by the Local Government Association. According to the web site it provides "secure online knowledge sharing for councillors and officers to connect and communicate with peers across government" (Local Government Association, 2012).

Supplementary questions asked respondents to share their recommendations for additional resources. In particular a number of additional sources of news about research results were identified. The majority were mailing lists, blogs and Twitter accounts.

Responses included comments on the usefulness of Twitter and other streaming news sources in leading to useful or interesting work. One approach is to create Twitter lists, such as http://twitter.com/imlaurie/digital-libraries, which tracks 39 librarians' tweets. The project Twitter account (@LIS_RiLIES) now follows over 250 twitter accounts of practitioners and organisations whose work is relevant to LIS research. It started lists on information sources (https://twitter.com/\#!/LIS_RiLIES/information-sources) (currently 33 members) and routes for research impact (https://twitter.com/\#!/LIS_RiLIES/researchimpact) (with 29 members), and providing a resource for the wider LIS community.

\subsection{Creating legacy resources: Options for project output}

The aim of the second group of questions in the survey was to establish priorities for the RiLIES project's outputs, with the supplementary aim of identifying any other types of material (as yet not identified by the project team) that could be considered.

As the Figure 3 shows, the core proposals generally attracted positive responses, although some doubt was expressed about the idea of a large poster. 


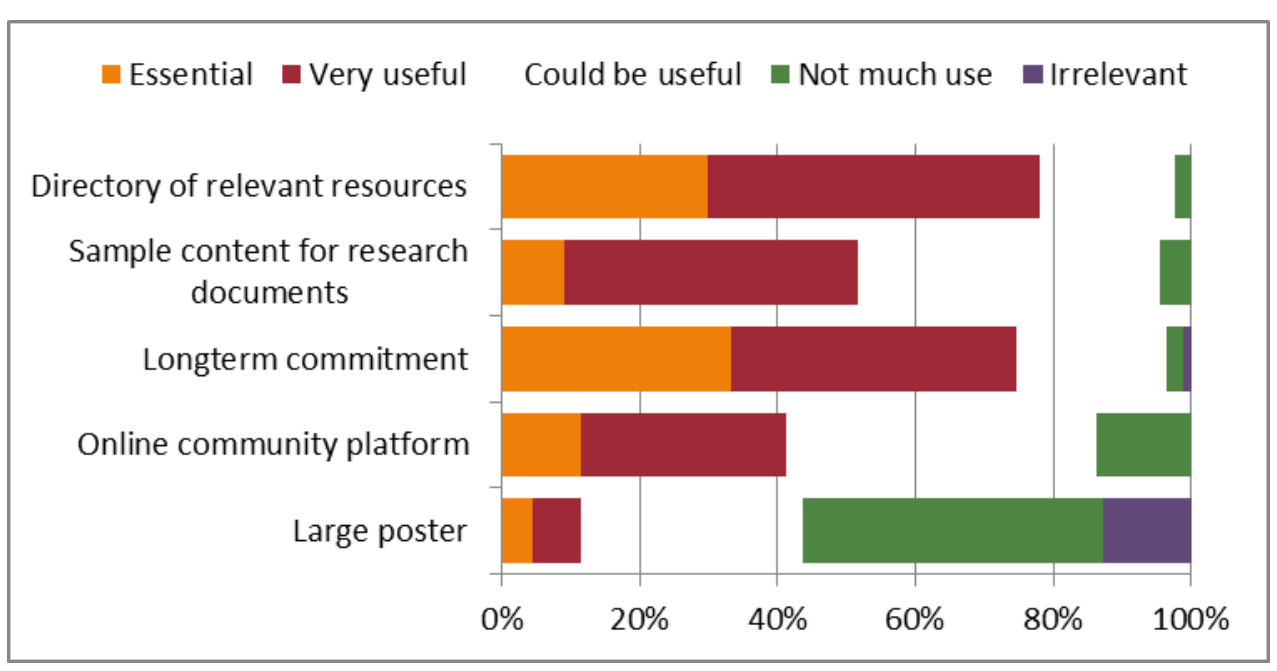

\section{Figure 3: Prioritising outputs for impact}

Some comments implied that a flyer/leaflet format might be better for communicating information about resources to help support LIS research. Tipsheets and brief, practical best practice guidelines on a broad range of topics were also suggested. However, it is recognised that such proposals only work in practice when a process is in place to ensure the content is kept up to date: there needs to be a long-term commitment to maintain any resources created.

Other suggestions from the survey included:

- Discussion space for questions and answers. The LIS community seems to be most happy using mailing-lists, so an approach may to either set up a new JISC LIS-* list, or to identify an existing list that could be used for discussion and support. LIS-LIRG would be an excellent candidate for this.

- Links to resources outside the UK which might address the low knowledge of US-based resources such as dLIST and RD.

Feedback also pointed out the need to maintain awareness of distinct areas of LIS practice. For instance library management is a very different subject area from information retrieval. Similarly, although some information sources are general, different sectors do have their own requirements.

\subsection{Spreading the word: dissemination options}

The final group of questions in the survey asked for feedback on the best way to publicise the RiLIES project's work. Perhaps predictably, given that the majority of respondents were from the academic sector, conventional routes were the most popular, so a project report and associated academic papers will remain core to the project's output. Preference was frequently expressed for open access journals. This may partly reflect a RiLIES1 finding that many LIS practitioners are not aware that CILIP membership gives access to many journal articles through subscriptions and online databases (CILIP, 2012). 


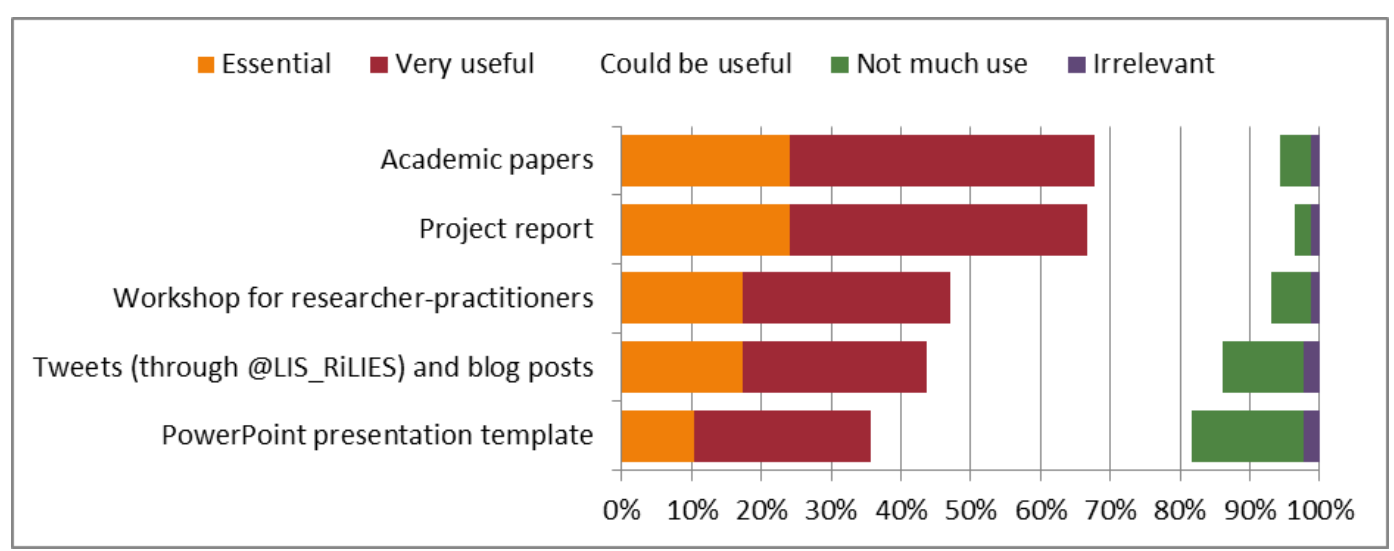

\section{Figure 4: Preferred dissemination options}

There was some support for the RiLIES2 team to create a PowerPoint presentation on LIS research resources for use in conferences and workshops, but also some expressed doubt over its usefulness. Since the RiLIES2 project results would be presented to audiences, it was still deemed logical to make presentation material used available for wider use, even if its ultimate take-up were low.

Some social media channels were explicitly mentioned as preferred routes for disseminating news of the RiLIES2 project. These included the (existing) Academic Librarian Facebook group, LinkedIn groups and (JISC) mailing lists. Blogging had some support (linked with RSS feeds), as had tools for information sharing such as bookmarking applications Diigo/Delicious. SlideShare was also mentioned several times.

Webinars and other forms of online presentations such as vodcast/podcast emerged several times as a route to reach people who cannot physically attend face-to-face dissemination events, and to act as a permanent record of the work completed. The challenge here is to make such material usable. At a minimum this would involve indexing videos, but could also include embedded hyperlinks and documents.

Suggested offline approaches for dissemination included publishing news items in the general and practitioner journals (e.g. CILIP, SCONUL Focus). Face to face routes were also mentioned, reflecting the importance attributed to this mode of communication in RiLIES1. Examples included informal talks to CILIP groups, workshops and conferences aimed at practitioners, piggy-backing on existing events.

\section{Conclusion}

In general, the RiLIES2 survey supported the assumptions behind the project. However, the low level of awareness of existing resources to support LIS research was surprising, especially given that the respondents to a survey such as this are likely to be more aware of research resources than the general LIS practitioner community.

The RiLIES2 team learnt from the survey results that the focus of the remainder of the project should be on the dissemination of information about existing resources and any new material should aim to highlight existing resources. 
A key finding was that respondents were less interested in seeing new materials (with the possible exception of brief guides to particular topics) than in having a directory of resources in a known location with (crucially) a long term commitment to maintenance. The Internet is already littered with abandoned or poorly maintained directories and out-of-date resources. In the current environment the only realistic approach would be to coordinate a community response, using tools that allow a joint approach to curation and to sharing of resources.

Given the available resources, in the short term, the most realistic and obvious option was to build on the existing content on the LIS Research Coalition site http://lisresearch.org/.

\section{References}

CILIP (2012). Online databases [online]. URL:

http://www.cilip.org.uk/membership/benefits/informed/online-

databases/pages/default.aspx [accessed 10.12.12].

Cruickshank P., Hall H. \& Taylor-Smith E. (2011). Enhancing the impact of LIS

Research: RiLIES project report [online]. URL:

http://www.researchinfonet.org/libraries/rilies/ [accessed 8.6.12].

Local Government Association (2012). Knowledge Hub [online]. URL:

https://knowledgehub.local.gov.uk/ [accessed 10.12.12].

\section{Acknowledgement}

We acknowledge the support from the LIS Research Coalition

(http://lisresearch.org) and its member bodies in supporting the RiLIES projects.

\section{Open access and copyright}

Library and Information Research is an open access journal. A freely available copy of this paper may be downloaded from the journal's website:

http://www.cilipjournals.org.uk/lir

Copyright and associated moral rights in works published in Library and Information Research are retained by the author(s) but this paper may be used freely, with proper attribution, in educational and other non-commercial settings. 